\title{
Knowledge, Attitude, and Practices Regarding HIV and TB Among Homeless People in Tehran, Iran
}

\author{
Fahimeh Bagheri Amiri ${ }^{1}$, Amin Doosti-Irani ${ }^{2,3}$, Abbas Sedaghat ${ }^{4,5}$, Noushin Fahimfar ${ }^{6,7}$, Ehsan Mostafavi ${ }^{3^{*}}$
}

\begin{abstract}
Background: Homeless people are at high risk of HIV and tuberculosis (TB) infection due to living in poor sanitary conditions and practicing high-risk behavior. The aim of this study is to assess the knowledge, attitude, and practice (KAP) of homeless people in Tehran regarding TB and HIV.

Methods: Using a convenience sampling, we performed a cross-sectional study on homeless people in Tehran from June to August 2012. Participants aged 18-60 years having at least 10 days of homelessness in the preceding month to the study period were included. All required data were collected through face-to-face interviews conducted using a researcherdesigned questionnaire. Each score in KAP of TB and HIV was separately divided by the maximum score and multiplied by 100 to attain percentage scores. The mean scores were compared using analysis of variance (ANOVA) and student's $t$ test. A Tukey test was used for post hoc analysis and two-by-two comparisons.

Results: In this study, 593 participants consisting of 513 men and 80 women were included. The mean age of the participants was $41.74 \pm 0.45$ years. Moreover, the total mean score of KAP toward HIV was 79.24 (95\% CI: 77.36 , 81.12), 57.13 (95\% CI: 55.12, 59.14), and 21.14 (95\% CI: 18.35, 23.93), respectively. The total mean score of knowledge and practice regarding TB was 62.04 (95\% CI: 59.94, 64.14) and 42.57 (95\% CI: 40.36, 44.78), respectively.

Conclusion: Although a relatively acceptable knowledge was detected in this high-risk population, practices regarding TB and HIV showed some weaknesses. Developing special programs to improve the healthy behavior of this population is highly recommended.

Keywords: Homeless, Tehran, KAP Study, HIV, Tuberculosis

Copyright: (C) 2018 The Author(s); Published by Kerman University of Medical Sciences. This is an open-access article distributed under the terms of the Creative Commons Attribution License (http://creativecommons.org/licenses/ by/4.0), which permits unrestricted use, distribution, and reproduction in any medium, provided the original work is properly cited.

Citation: Bagheri Amiri F, Doosti-Irani A, Sedaghat A, Fahimfar N, Mostafavi E. Knowledge, attitude, and practices regarding HIV and TB among homeless people in Tehran, Iran. Int J Health Policy Manag. 2018;7(6):549-555. doi:10.15171/ijhpm.2017.129
\end{abstract}

\section{Article History:}

Received: 23 November 2016 Accepted: 22 October 2017 ePublished: 7 November 2017

\footnotetext{
*Correspondence to:

Ehsan Mostafavi

Email: mostafavi@pasteur.ac.ir
}

\section{Key Messages}

Implications for policy makers

- Educational and counseling programs in prisons, harm reduction centers, and shelters can help governors prevent high-risk behaviors in homeless people.

- A concerted national strategy is needed to decrease the size of the homeless population.

Implications for the public

Homeless people are more vulnerable to infectious diseases due to their poor nutrition, high-risk behavior, and low knowledge. The relation between homeless people and the general population is documented, especially in the area of HIV. These connections may result in transmission of diseases such as HIV to low-risk populations. Understanding the baseline status of knowledge, attitude, and practice (KAP) in homeless people can help the policymakers to find the gaps and develop specific programs accordingly.

\section{Introduction}

The acquired immunodeficiency syndrome (AIDS) has become a pandemic threat to the world population. ${ }^{1}$ After the introduction of the HIV in $1983,{ }^{2}$ the disease was first reported in Iran (a boy with hemophilia) in 1986. Based on national reports, a total of $34846 \mathrm{HIV}$-infected people have been identified in Iran until December 2016. However, according to the estimates, there are over 76000 people living with HIV in Iran. The most predominant method of HIV transmission in Iran is injection drug use, with sexual contact has been recently acknowledged as an important mode of transmission. Educational programs have been introduced as an important tool to HIV prevention. ${ }^{3}$

$\mathrm{HIV}$ is the most significant known risk factor for activation of latent tuberculosis infection (LTBI). The risk of active tuberculosis (TB) for people with both LTBI and HIV reaches 
$8 \%$ to $10 \%$ per year, whereas this same risk for people without $\mathrm{HIV}$ infection is $5 \%$ to $10 \%$ in a lifetime. ${ }^{4,5}$ It has to be noted that TB may be the first indicator of HIV infection. ${ }^{6,7}$

Factors such as low income, living and working in substandard conditions, limited access to nutrition and proper healthcare services predispose people to diseases like TB. Occupations such as miners, construction workers, and health care workers, and prisoners and people who live and work in improper conditions have a higher risk of TB. ${ }^{8}$

Homeless people are individuals who either have no place to sleep or sleep in public or private shelters. An estimated 100 million people are homeless worldwide. The number of homeless is increasing in Tehran and other big cities of Iran, as 4811 homeless were registered in Eslamshahr center in 2008-2009.9 The number of registered homeless females rose during 2006-2011. ${ }^{10}$ The fatality rate among this group of people is almost 4 times higher than that of the general population. ${ }^{11}$

Homelessness is associated with social, behavioral, and environmental hazards that make homeless people vulnerable to communicable diseases and make a public health concern. Due to their specific lifestyle, high-risk behaviors such as drug use, needle sharing, and selling sex, HIV risk is higher in homeless people. ${ }^{3,12-14}$ It seems that homelessness can potentially rise due to increasing impulsive behaviors. ${ }^{15}$

Also, these groups are increasingly at risk for exposure to Mycobacterium tuberculosis and consequently develop active TB with a co-infection of TB and HIV. ${ }^{16,17}$ According to an unofficial report, more than 18000 homeless are living in Tehran. One useful way to decrease undesirable consequences induced by infectious diseases is to improve the health interventions.

Understanding the baseline status of knowledge, attitude, and practice (KAP) in the target population is necessary. Although there are some studies conducted in Iran concerning the KAP of various high-risk groups, ${ }^{18-20}$ homeless people have not been targeted yet. The present study was conducted to define the KAP of this population in Tehran regarding TB and HIV.

\section{Methods}

\section{Study Population}

We conducted a cross-sectional study on the homeless people in five centers sponsored by the municipality of Tehran from June to August 2012. These centers are the whereabouts of homeless people in Tehran that collect this group from the corners of streets, in parks, or in public places and keep them temporarily.

In this study, a homeless person is defined as someone who had no home or shelter to reside in and instead resides on the corners of streets, in parks, or in public places, if he/she is not provided with a residence provided by the governmental or non-governmental organizations. ${ }^{11,12}$ Inclusion criteria of this study are the willingness to participate in the study, having an age of 18 to 60 years, and being homeless for at least 10 days during the month prior to the study period either continuously or intermittently. Exclusion criteria, on the other hand, are a reluctance to participate in the study and participation in another similar study.
Data Collection

In this study, a bio-behavioral survey among homeless people was employed. It is worth mentioning that the results of the survey regarding the prevalence of communicable disease have been published elsewhere. ${ }^{21}$

Before approve approved, several meetings were held by the municipality, state welfare organization of Tehran, and Social Security police. Through these meetings, the researchers introduced the main service provider centers for homeless in Tehran. The Municipality of Tehran provided shelters, a bed, two meals a day, health services, and counseling for homeless people. ${ }^{21}$ They could enter and exit freely only in two centers (Bahman and Khavaran shelters) while in the other centers homeless are brought by the police force and had prohibition of exit until spending courses and specific terms. Sampling was done in five centers including Khavaran, Bahman, Lavizan, and EslamShahr shelters, and Shafagh camp.

Since there was no specific questionnaire designed for homeless people, a questionnaire in Persian was developed to achieve the required information. For this purpose, some previous body of evidence in $\operatorname{Iran}^{20,22}$ and related indicators in international reports were reviewed to address more important issues in high-risk populations.

The questionnaire consists of six sections as follows: (a) demographic characteristics; (b) six questions related to knowledge of HIV (one point for each question) with a total score between zero and six; (c) three five-choice questions related to attitude toward HIV (strongly disagree $=5$, disagree $=4$, no idea $=3$, agree $=2$, and strongly agree $=1$ ) with a total score between zero and $15 ;(d)$ two questions related to practice (one point for each question) regarding HIV with a total score between zero and two; (e) five questions related to knowledge of TB (one point for each question) with a total score between zero and five; and $(f)$ two questions about practice regarding $\mathrm{TB}$ (one point for each question) with a total score between zero and two. Each HIV and TB KAPs score was divided by the maximum score and multiplied by 100 to obtain percentage scores.

A panel of an expert in the field of TB and HIV epidemiology evaluated the validity of the questionnaire. The reliability of the questionnaire (ie, 0.69 ) was also investigated by the test and retest technique with an interval of one week. Interviews and questioning were conducted by trained interviewers. All participants were screened if they had heard anything about TB or HIV. Next, KAP questions were filled by people who had heard anything about TB or HIV.

\section{Statistical Analysis}

An analysis of variance (ANOVA) and a student's $t$ test were used to compare the mean score of KAP across subgroups. A Tukey test was used for post hoc analysis and two-bytwo comparisons. All analyses were performed at a $95 \%$ confidence level using SPSS 16.

\section{Results}

In this study, a total of 593 participants were interviewed; the mean \pm standard error of mean (SEM) age of the participants was $41.74 \pm 10.77$ years, males were significantly older 
$(42.74 \pm 10.56)$ than females $(35.46 \pm 9.96)(P=.001)$. The mean duration of homelessness was $50.71 \pm 78.17$ months. Study participants were predominantly males $(86.51 \%)$ who had a more homelessness duration (50.71 \pm 78.18 months) compared to females' homeless duration (12.68 \pm 25.87 month $)(P=.001)$. Basic characteristics of the recruited homeless subjects are shown in Table 1.

\section{Knowledge, Attitude, and Practice About HIV}

Only 395 participants ( $70.30 \%$ of males and $50 \%$ of females) had heard something about HIV while $28.42 \%$ of them considered themselves at risk for HIV (Table 2). In this regard, there was no significant difference between males and females $(P=.43)$.

The total mean score of knowledge toward HIV was 79.24 (95\% CI: 77.36, 81.12). The mean score of knowledge among males (80.42) was more than that of female (68.75) significantly $(P=.001)$. Compared the illiterate people, a significantly higher knowledge of HIV was detected in people with the academic education $(P=.02)$. The mean score of attitude in

Table 1. Basic Demographic Characteristics of Homeless People of Tehran, 2012

\begin{tabular}{|c|c|c|}
\hline Variable & No. $(n=593)$ & $\%$ \\
\hline \multicolumn{3}{|l|}{ Gender } \\
\hline Female & 80 & 13.49 \\
\hline Male & 513 & 86.51 \\
\hline \multicolumn{3}{|l|}{ Age group } \\
\hline $18-29$ & 85 & 14.62 \\
\hline $30-39$ & 175 & 30.12 \\
\hline $40-49$ & 138 & 23.75 \\
\hline$\geq 50$ & 183 & 31.50 \\
\hline \multicolumn{3}{|l|}{ Marriage } \\
\hline Single & 117 & 24.48 \\
\hline Married & 71 & 14.85 \\
\hline Divorced/widowed & 290 & 60.67 \\
\hline \multicolumn{3}{|l|}{ Education } \\
\hline Illiterate & 68 & 11.83 \\
\hline Can read and write/primary school & 145 & 29.74 \\
\hline Secondary school & 155 & 26.96 \\
\hline High school/diploma & 155 & 26.96 \\
\hline Post high school & 52 & 9.04 \\
\hline \multicolumn{3}{|l|}{ Homelessness duration } \\
\hline 10 days -5 months & 146 & 25.70 \\
\hline 5-24 months & 171 & 30.11 \\
\hline 24-60 months & 118 & 20.77 \\
\hline$\leq 60$ months & 133 & 23.42 \\
\hline \multicolumn{3}{|l|}{ History of incarceration } \\
\hline Never & 298 & 51.20 \\
\hline More than 10 years ago & 69 & 11.86 \\
\hline Within the last 10 years & 215 & 36.94 \\
\hline \multicolumn{3}{|l|}{ Duration of incarceration (in the last 10 years) } \\
\hline More than 11 months & 107 & 50.23 \\
\hline Less than 11 months & 106 & 49.77 \\
\hline Using condom in last sexual contact & 154 & 33.19 \\
\hline History of sharing needles & 64 & 52.46 \\
\hline History of having sex with males among males & 36 & 7.02 \\
\hline History of selling sex among women & 14 & 17.50 \\
\hline Smoking cigarettes regularly ${ }^{a}$ & 507 & 85.49 \\
\hline Smoking hookah & 108 & 18.21 \\
\hline
\end{tabular}

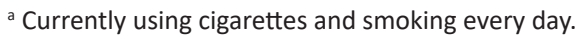

educational groups was significantly different $(P<.001)$ and people with an elementary level of education had the lowest score of attitude. The mean score of attitude toward HIV was different in terms of marital status $(P=.03)$ as it was higher in single people compared to the married ones. The total mean score of practice toward prevention of HIV was 21.14 (95\% CI: 18.35, 23.93). However, practice score among males was significantly less than females $(P=.001)$. In addition, in post hoc analysis, the score of practice among age groups was different $(P=.045)$ and people aged 41-51 years had a higher score compared to those over 51 years (Table 3 ).

In this study, $82.39 \%$ of the participants knew condoms as a preventive tool for protection against HIV and $35.63 \%$ of them had used this tool in their last sexual intercourse. Males had more knowledge about the preventive role of condoms in HIV transmission. On the other hand, women reported significantly more condom use in their last sexual intercourse (69.44\% vs. $31.10 \%, P<.001)$.

Over $90 \%$ of participants knew needle sharing is one method of HIV transmission and $13.62 \%$ of them had a history of needle sharing.

Totally, 93\% of participants knew the possibility of HIV transmission through unprotected sex between men. Of 367 males who answered correctly to this question, 29 (7.90\%) had experienced sex with other men. Generally, 14 women (17.50\%) reported prostitution in their lifetime, and 11 (78.57\%) of them had heard about HIV.

\section{Knowledge, Attitude, and Practice About Tuberculosis}

In this study, $343(57.84 \%)$ participants $(62.18 \%$ of males and $36.70 \%$ of females, $P<.001$ ) had heard about TB and $36.95 \%$ of them considered themselves at risk of TB. In this regard, there was no significant difference between males and females $(P=.22)$ (Table 2).

The total mean score of knowledge about TB was 62.04 (95\% CI: 59.94, 64.14).

Post hoc analysis showed that people with a high education had more knowledge of TB in comparison to illiterate people $(P=.002)$, but no significant difference was detected with other education levels. The overall mean score of practice toward TB was 42.57 (95\% CI: 40.36, 44.78). The mean score of practice among males was more than that of females $(P=.001)$ (Table 4).

Only 301 participants (50.76\%) had heard about both HIV and $\mathrm{TB}$, of whom 14 (4.65\%) subjects had comprehensive knowledge about both HIV and TB.

\section{Discussion}

In this study, $66.61 \%$ and $58.73 \%$ of the participants declared that they had heard about HIV and TB, respectively. This percentage was lower for other groups considered at risk for HIV (female sex workers, prisoners, and injection drug users [IDU]) in Tehran. ${ }^{20}$

In this study, only $66.61 \%$ of homeless participants have heard about HIV/AIDS that is much lower than the results of the surveys on female sex workers (FSWs) (92.70\%), IDUs (96.93\%), and prisoners (93.19\%). ${ }^{20}$ This result shows that although education programs about the communicable 
Table 2. Descriptive Analysis Regarding General HIV and TB Knowledge and Attitude of Homeless People in Tehran, 2012

\begin{tabular}{|c|c|}
\hline Question & No. (\%) of Positive Answers \\
\hline \multicolumn{2}{|l|}{ HIV } \\
\hline Have you ever heard anything about HIV/AIDS? & $395(66.61)$ \\
\hline \multicolumn{2}{|l|}{ Knowledge about HIV } \\
\hline Can using condoms reduce the risk of HIV transmission? & $323(82.39)$ \\
\hline Can a healthy looking person have HIV? & $296(75.70)$ \\
\hline Can a person get HIV from mosquito bites? & $197(49.87)$ \\
\hline Can a person get HIV by sharing a meal with someone who is infected? & $229(57.97)$ \\
\hline Can HIV be transmitted via sharing syringes or needles with others? & 369 (93.89) \\
\hline Can HIV be transmitted via sex between two men? & $367(93.15)$ \\
\hline \multicolumn{2}{|l|}{ Attitude toward HIV } \\
\hline Do you consider yourself at risk of HIV? & $110(28.42)$ \\
\hline HIV positive people should be isolated from the general population. & $206(52.41)$ \\
\hline The presence of an HIV positive person makes a family embarrassed. & $157(40.67)$ \\
\hline Would you share a meal with a person who is positive for HIV/AIDS? & $163(42.12)$ \\
\hline \multicolumn{2}{|l|}{ TB } \\
\hline Have you ever heard anything about TB? & $343(58.73)$ \\
\hline \multicolumn{2}{|l|}{ Knowledge about TB } \\
\hline Does TB spread by respiratory route? & $296(86.30)$ \\
\hline Can a person get TB by sharing a meal with someone who is infected? & $122(35.67)$ \\
\hline Can TB be transmitted via sharing syringes or needles with others? & $122(35.88)$ \\
\hline Does living with a TB infected person raise the risk of getting a TB infection? & $279(83.80)$ \\
\hline Is TB a treatable disease? & $245(72.70)$ \\
\hline Do you consider yourself at risk of TB? & $126(36.95)$ \\
\hline \multicolumn{2}{|l|}{ Practice regarding TB } \\
\hline Smoking cigarettes regularly & $507(85.49)$ \\
\hline Smoking hookah & $108(18.21)$ \\
\hline
\end{tabular}

Abbreviation: TB, tuberculosis.

disease for high-risk people such as FSWs, IDUs, and prisoners have been recently improved in Iran, it still covers a low population of homeless.

These results indicate a gap between the scores of knowledge and practice among participants regarding HIV and TB. The results of our study indicate a higher mean score of knowledge about HIV (79.24) than the results of a meta-analysis (67.51) conducted in Iran. ${ }^{23}$ In a cross-sectional study in 13 provinces of Iran on young people, less than $40 \%$ of participants had a high knowledge score about HIV. ${ }^{22}$ Participants in our study may have received further information about HIV through educational programs or counseling in jails, shelters, addiction treatment centers, etc. A reason for a gap between scores of knowledge and practice regarding HIV may be due to the lack of discretion in the use of a condom, especially among female homeless people. On the other hand, some factors such as lack of social and emotional support, and economic poverty among homeless people could affect the behaviors of these people. Another reason for this difference may be the lower number of knowledge questions in our study.

In this study, the negative attitude of the participants about HIV was consistent with another study. ${ }^{24}$ Over $90 \%$ of participants in our study were aware of the risk of HIV transmission via contaminated syringes. The awareness of this transmission method is common in Iran because of the design and implementation of educational programs for different groups in recent years. Similar to our study, most studies have results over $80 \%$ of participants knowing the transmission methods of $\mathrm{HIV}^{18,20,25,26}$
In our study, about $93 \%$ of participants knew homosexual intercourse as a risk factor for transmission of HIV. Although $36(7.02 \%)$ of all male participants reported a history of homosexual contact, considering the stigmatized nature of this behavior in our public opinion that may lead to refuse disclosure, the real prevalence of this behavior might be higher among this high-risk population.

Contrary to the high mean score of knowledge about HIV among men $(P=.001)$, the mean score of practice was significantly lower for males $(P=.001)$. A reason for this difference may be due to significantly more condom use in females compared to the males in their last intercourse. These results may indicate that, despite the lower knowledge of women, they are more cautious about their health than men. It can also be explained by the fact that women may use a condom for prevention of unwanted pregnancy without knowing that using condoms prevents HIV transmission. In line with some similar studies, ${ }^{19}$ the knowledge level of men about the preventive role of condoms in the prevention of HIV was higher than that of women. Condom use was also more reported among homeless African-American female teenagers than men $^{27}$ while another study on Mexican adolescents indicated the opposite of this finding. ${ }^{28}$

The mean score of practice among men, however, was lower than that of women. An explanation for this result may be the higher mean age of men than women, as condom use often decreases with increasing age. ${ }^{11}$ Inconsistent with this finding, in a qualitative study on socially damaged women, it was found that the main reason for having unprotected sex by $88 \%$ of the 
Table 3. Distribution of KAP Mean Score Percentages for Participants Who Heard About HIVIAIDS, Tehran, 2012ª

\begin{tabular}{|c|c|c|c|c|c|c|c|}
\hline \multirow{2}{*}{ Variable } & \multirow{2}{*}{$\mathbf{N}$} & Knowledge & \multirow{2}{*}{$P$ value } & Attitude & \multirow{2}{*}{$P$ Value } & Practice & \multirow{2}{*}{$P$ Value } \\
\hline & & Mean $(95 \% \mathrm{Cl})$ & & Mean $(95 \% \mathrm{Cl})$ & & Mean $(95 \% \mathrm{Cl})$ & \\
\hline \multicolumn{8}{|l|}{ Gender } \\
\hline Female & 40 & $68.75(63.37,74.13)$ & \multirow{2}{*}{.001} & $54.67(48.61,60.73)$ & \multirow{2}{*}{.42} & $35.00(27.00,43.00)$ & \multirow{2}{*}{.001} \\
\hline Male & 355 & $80.42(78.45,82.39)$ & & $57.41(55.28,59.54)$ & & $19.58(16.65,22.51)$ & \\
\hline \multicolumn{8}{|l|}{ Age group } \\
\hline $18-29$ & 50 & 74.67 (69.58-79.75) & \multirow{4}{*}{.06} & $59.60(53.70-65.50)$ & \multirow{4}{*}{.48} & $24.00(15.76-32.24)$ & \multirow{4}{*}{.004} \\
\hline $30-39$ & 129 & 79.06 (75.66-82.48) & & 56.33 (52.94-59.72) & & $21.32(16.48-26.16)$ & \\
\hline $40-49$ & 86 & 83.53 (79.95-87.10) & & 59.46 (54.4-64.27) & & $29.07(22.00-36.14)$ & \\
\hline$\geq 50$ & 126 & 78.57 (74.99-82.15) & & 55.87 (52.37-59.38) & & 15.08 (10.86-19.29) & \\
\hline \multicolumn{8}{|l|}{ Marital status } \\
\hline Single & 82 & 80. 08 (10.51, 19.89) & \multirow{4}{*}{.31} & $61.54(57.14,65.94)$ & \multirow{4}{*}{.03} & $28.05(21.23,34.87)$ & \multirow{4}{*}{.30} \\
\hline Married & 46 & $77.90(73.59,82.21)$ & & $50.58(44.44,56.72)$ & & $26.09(18.18,34.00)$ & \\
\hline Divorced & 184 & $78.71(75.94,81.43)$ & & $58.33(55.49,61.17)$ & & $21.47(17.34,25.60)$ & \\
\hline Widowed & 23 & $86.23(79.84,92.98)$ & & $60.57(52.07,60.38)$ & & $19.57(6.96,32.17)$ & \\
\hline \multicolumn{8}{|l|}{ Education } \\
\hline Illiterate & 29 & $74.71(67.71,81.71)$ & \multirow{5}{*}{.001} & $51.26(44.97,57.55)$ & \multirow{5}{*}{.001} & $17.24(7.18,27.30)$ & \multirow{5}{*}{0.32} \\
\hline Primary & 77 & $67.75(63.46,72.04)$ & & $48.14(43.95,52.33)$ & & $16.23(10.66,21.80)$ & \\
\hline Secondary school & 105 & $81.59(78.23,84.95)$ & & $58.92(55.27,62.57)$ & & $20.48(14.90,26.06)$ & \\
\hline High school/diploma & 129 & $82.04(78.83,85.25)$ & & $59.69(56.02,63.36)$ & & $23.26(18.31,28.21)$ & \\
\hline Post high school & 47 & $87.59(83.58,91.60)$ & & $62.55(56.81,68.29)$ & & $25.53(16.65,34.41)$ & \\
\hline \multicolumn{8}{|l|}{ Homeless duration (months) } \\
\hline 5-10 days & 85 & $79.80(76.01,83.59)$ & \multirow{4}{*}{.50} & $56.16(51.79,60.53)$ & \multirow{4}{*}{.52} & $22.94(16.47,29.41)$ & \multirow{4}{*}{0.75} \\
\hline $5-24$ & 124 & $81.18(77.79,84.57)$ & & $56.13(52.56,59.70)$ & & $20.97(16.33,25.61)$ & \\
\hline $24-60$ & 82 & $77.44(73.66,81.22)$ & & $58.46(54.22,62.70)$ & & $22.56(16.16,28.96)$ & \\
\hline$\leq 60$ & 96 & $78.30(74.31,82.29)$ & & $58.96(54.70,63.22)$ & & $18.75(13.08,24.42)$ & \\
\hline \multicolumn{8}{|l|}{ History of incarceration } \\
\hline Never & 173 & $76.69(73.64,79.74)$ & \multirow{3}{*}{.07} & $57.96(54.98,60.94)$ & \multirow{3}{*}{.07} & $19.65(15.74,23.56)$ & \\
\hline More than 10 years ago & 52 & $81.42(77.06,85.78)$ & & $50.90(45.61,56.19)$ & & $22.11(13.85,30.37)$ & 0.64 \\
\hline Within the last 10 years & 167 & $81.14(78.36,83.92)$ & & $58.00(54.83,61.17)$ & & $22.46(17.93,26.99)$ & \\
\hline Duration of Incarceration ( & 10 ye & & & & & & \\
\hline More than 9 months & 85 & $80.39(76.60,84.18)$ & 60 & $57.41(53.00,61.82)$ & 72 & $21.18(15.18,27.18)$ & 063 \\
\hline Less than 9 months & 81 & $81.89(77.74,86.04)$ & .00 & $58.60(53.95,63.25)$ & .12 & $23.46(16.55,30.37)$ & 0.03 \\
\hline Total & 395 & $79.24(77.36,81.12)$ & - & $57.13(55.12,59.14)$ & - & $21.14(18.35,23.93)$ & - \\
\hline
\end{tabular}

Abbreviation: KAP, knowledge, attitude, and practice.

a Participants' scores of KAP are calculated out of 100.

participants was lack of authority to make decisions on the sexual contacts and use of condoms. ${ }^{29}$ Generally, in our study, the frequency of condom use among homeless people was low, as indicated in other high-risk groups. ${ }^{20}$ The main reasons for this practice, especially in Iran, maybe unavailability and cost issues. ${ }^{30}$ Most people who sell sex (either male or female) to obtain goods or drugs or women who are forced into the sex trade by their addicted relatives, do not have a choice in using condoms, as this decision usually remains by their sexual partners..$^{29,31,32}$

The mean score of TB knowledge in this study (62.04) was higher than that of the Los Angeles homeless (57.31). ${ }^{33}$ Although there was no significant difference between knowledge of men and women regarding TB, the mean score of practice about TB among men was significantly higher than that of women. The significant impact of knowledge and practice regarding TB on effective control of this infection among homeless is clear. ${ }^{34}$ Poor knowledge about TB may foster treatment delays. ${ }^{35}$

In this study, knowledge of educated people was high toward HIV and TB. There was, though, no significant difference in practice toward HIV and TB among people with different levels of education.

Therefore, it is implied that having the knowledge and even changing attitude does not necessarily lead to change in practice. For effective impact on all three fields, we need more comprehensive educational programs. The risk of HIV should be tangible for homeless people with high-risk behaviors. In the educational programs, the volunteer people living with HIV and AIDS can have an effective role with their peer support. ${ }^{36}$

This study had limitations for the number of required questions to complete evaluation of HIV and TB KAP. Such limitations are attributed to fact that the original study was so wide and its primary aim was to assess the prevalence of HIV, viral hepatitis, and TB among homeless people. Another limitation of this study is that there was only one question to assess the attitude of the participants about TB in the original questionnaires.

Moreover, this study was a facility-based survey and it was not possible to include the homeless people who had not been engaged in shelters. Thus, we should be cautious to generalize the results to all homeless population. 
Table 4. Distribution of percent KAP mean scores for participants who heard about TB, Tehran 2012

\begin{tabular}{|c|c|c|c|c|c|}
\hline \multirow{2}{*}{ Variable } & \multirow{2}{*}{$\mathbf{N}$} & Knowledge & \multirow{2}{*}{$P$ Value } & Practice & \multirow{2}{*}{$P$ Value } \\
\hline & & Mean $(95 \% \mathrm{Cl})$ & & Mean $(95 \% \mathrm{Cl})$ & \\
\hline \multicolumn{6}{|l|}{ Gender } \\
\hline Female & 29 & $61.37(52.26,70.48)$ & \multirow{2}{*}{.85} & $27.58(18.37,36.79)$ & \multirow{2}{*}{.002} \\
\hline Male & 314 & $62.10(59.96,64.24)$ & & $43.94(41.74,46.14)$ & \\
\hline \multicolumn{6}{|l|}{ Age group } \\
\hline $18-29$ & 39 & $64.62(57.11-72.12)$ & \multirow{4}{*}{.64} & 37.18 (28.29-47.07) & \multirow{4}{*}{.11} \\
\hline $30-39$ & 91 & 63.52 (59.10-67.63) & & $40.11(35.66-44.56)$ & \\
\hline $40-49$ & 81 & 61.23 (57.14-65.33) & & 45.68 (41.69-49.66) & \\
\hline$\geq 50$ & 129 & 60.93 (59.99-64.24) & & $43.41(40.07-44.56)$ & \\
\hline \multicolumn{6}{|l|}{ Marital status } \\
\hline Single & 70 & $64.00(59.09,68.91)$ & \multirow{4}{*}{.84} & $36.43(30.04,42,82)$ & \multirow{4}{*}{.09} \\
\hline Married & 47 & $61.70(55.60,67.80)$ & & $42.55(37.27,47.83)$ & \\
\hline Divorced & 159 & $62.14(59.05,65.22)$ & & $44.03(40.93,47.13)$ & \\
\hline Widowed & 19 & $65.26(56.26,74.26)$ & & $44.74(37.14,52.33)$ & \\
\hline \multicolumn{6}{|l|}{ Education } \\
\hline Illiterate & 30 & $56.00(49.09,62.91)$ & \multirow{5}{*}{.001} & $41.67(34.59,48.74)$ & \multirow{5}{*}{.12} \\
\hline Primary & 70 & $56.57(51.98,61.16)$ & & $43.57(38.23,48.91)$ & \\
\hline Secondary school & 82 & $60.73(56.39,65.07)$ & & $38.41(33.75,43.08)$ & \\
\hline High school/diploma & 109 & $63.85(60.07,67.39)$ & & $42.67(38.61,46.71)$ & \\
\hline Post high school & 45 & $70.67(65.29,76.04)$ & & $48.89(43.83,53.94)$ & \\
\hline \multicolumn{6}{|l|}{ Homeless duration (months) } \\
\hline 5-10 days & 70 & $63.71(58.19,62.24)$ & \multirow{4}{*}{.71} & $40.00(34.79,45.21)$ & \multirow{4}{*}{.38} \\
\hline $5-24$ & 101 & $60.59(56.83,64.36)$ & & $40.59(36.47,44.71)$ & \\
\hline $24-60$ & 79 & $62.78(57.87,66.70)$ & & $43.67(39.51,47.93)$ & \\
\hline$\leq 60$ & 86 & $60.93(56.78,65.08)$ & & $44.77(40.11,49,43)$ & \\
\hline \multicolumn{6}{|l|}{ History of incarceration } \\
\hline Never & 157 & $60.38(57.08,63.68)$ & \multirow{3}{*}{.33} & $41.40(37.92,44.88)$ & \multirow{3}{*}{.66} \\
\hline More than 10 years ago & 42 & $63.81(57.93,69.69)$ & & $44.05(37.89,50.21)$ & \\
\hline Within the last 10 years & 141 & $63.54(60.38,66.71)$ & & $43.26(39.93,45.60)$ & \\
\hline \multicolumn{6}{|c|}{ Duration of Incarceration (in the last 10 years) } \\
\hline More than 9 month & 73 & $61.92(57.52,66.32)$ & \multirow{3}{*}{.33} & $41.78(37.09,46.47)$ & \multirow{3}{*}{.38} \\
\hline Less than 9 month & 67 & $65.07(60.55,69.59)$ & & $44.78(40.06,49.50)$ & \\
\hline Total & 343 & $62.04(59.94,64.14)$ & & $42.57(40.36,44.78)$ & \\
\hline
\end{tabular}

Abbreviations: KAP, knowledge, attitude, and practice; TB, tuberculosis.

a Participants' scores of knowledge and practice are calculated out of 100.

\section{Conclusion}

The results of our study showed a major gap among KAP regarding HIV and also between knowledge and practice toward TB. Rescuing street children, improving their living conditions, and providing educational programs can prevent them from committing high-risk behaviors in the future. Also, educational and counseling programs in prisons, harm reduction centers, and shelters can be useful to prevent from high-risk behaviors in these groups.

\section{Acknowledgments}

Our special thanks go to the research committee and the ethical committee of the Pasteur Institute of Iran, Tehran, Iran which approved this project (No. 1716) and the Center for Communicable Disease Control in the Ministry of Health and Medical Education (MoHME), Tehran, Iran which financially supported this project. The research team is grateful for the technical support of Dr. Ali Akbar Haghdoost (WHO Collaboration Center, Regional Knowledge Hub for HIV/ AIDS Surveillance, Kerman, Iran), for the logistical support of Dr. Saber Esmaeili (Pasteur Institute of Iran, Tehran, Iran), Dr. Zahra Bolouki (Tehran University of Medical Sciences, Tehran, Iran) and Dr. Fereshteh Ansari (University of Tehran,
Tehran, Iran) and all the Tehran municipality centers which helped us with the sampling process. This project was supported by Centre for Communicable Disease Control in the MoHME, Tehran, Iran (Grant No. 1716).

\section{Ethical issues Tehran, Iran (No. 1716). \\ Competing interests \\ Authors declare that they have no competing interests.}

This study was approved by ethical committee of Pasture Institute of Iran,

Authors' contributions

FBA, $A D$, and $E M$ obtained the data, performed analyses, and wrote results. EM, FBA, and AS took a lead in review of literature. All five authors contributed to discussion and conclusions.

Authors' affiliations
'Urology and Nephrology Research Center, Shahid Beheshti University of
Medical Sciences, Tehran, Iran. '2Department of Epidemiology, School of
Public Health, Hamadan University of Medical Sciences, Hamadan, Iran.
${ }^{3}$ Department of Epidemiology and Biostatistics, Research Centre for Emerging
and Reemerging Infectious Diseases, Pasteur Institute of Iran, Tehran, Iran.
${ }^{4}$ Blood Transfusion Research Center, High Institute for Research and Education
in Transfusion Medicine, Tehran, Iran. ${ }^{5}$ Center for Communicable Disease
Control, Ministry of Health and Medical Education, Tehran, Iran. ${ }^{6}$ Department
of Epidemiology and Biostatistics, School of Public Health, Tehran University 
of Medical Sciences, Tehran, Iran. ${ }^{7}$ HIVISTI Surveillance Research Center, and WHO Collaborating Center for HIV Surveillance, Institute for Futures Studies in Health, Kerman University of Medical Sciences, Kerman, Iran.

\section{References}

1. Tavoosi A, Zaferani A, Enzevaei A, Tajik P, Ahmadinezhad Z. Knowledge and attitude towards HIVIAIDS among Iranian students. BMC Public Health. 2004;4:17. doi:10.1186/14712458-4-17

2. Gallo RC, Montagnier L. The discovery of HIV as the cause of AIDS. N Engl J Med. 2003;349(24):2283-2285. doi:10.1056/ NEJMp038194

3. Skevington SM, Sovetkina EC, Gillison FB. A systematic review to quantitatively evaluate 'Stepping Stones': a participatory community-based HIVIAIDS prevention intervention. AIDS Behav. 2013;17(3):1025-1039. doi:10.1007/s10461-012-0327-6

4. Aaron L, Saadoun D, Calatroni I, et al. Tuberculosis in HIVinfected patients: a comprehensive review. Clin Microbiol Infect. 2004;10(5):388-398. doi:10.1111/j.1469-0691.2004.00758.x

5. Pawlowski A, Jansson M, Skold M, Rottenberg ME, Kallenius G. Tuberculosis and HIV co-infection. PLoS Pathog. 2012;8(2):e1002464. doi:10.1371/journal.ppat.1002464

6. Getahun H, Kittikraisak W, Heilig CM, et al. Development of a standardized screening rule for tuberculosis in people living with HIV in resource-constrained settings: individual participant data meta-analysis of observational studies. PLoS Med. 2011;8(1):e1000391. doi:10.1371/journal.pmed.1000391

7. Havlir DV, Getahun H, Sanne I, Nunn P. Opportunities and challenges for HIV care in overlapping HIV and TB epidemics. JAMA. 2008;300(4):423-430. doi:10.1001/jama.300.4.423

8. World Health Organization. Working together with businesses: guidance on TB and TB/HIV prevention, diagnosis, treatment and care in the workplace. Geneva: WHO; 2012.

9. Salarzadeh AN, Mohammadi B. Investigating the effects of socio-economic factors on homeless people of Tehran. Social Development and Welfare Planning. 2010;1(1):93-110.

10. Safiri K, Khadem R. An evaluation of life expectancy status among homeless women in tehran city (case of study: a temporary holding center for homeless women of tehran municipality, "samansraye lavizan"). Journal of Iranian Social Development Studies. 2014;6(1):51-70.

11. Amiri FB, Gouya MM, Saifi M, et al. Vulnerability of homeless people in Tehran, Iran, to HIV, tuberculosis and viral hepatitis. PLoS One. 2014;9(6):e98742. doi:10.1371/journal. pone.0098742

12. Amiri FB, Sedaghat A, Mostafavi E. Gender differences among homeless people in Tehran, Iran. J Public Health. 2014;22(5):461465. doi:10.1007/s10389-014-0633-8

13. Corneil TA, Kuyper LM, Shoveller J, et al. Unstable housing, associated risk behaviour, and increased risk for HIV infection among injection drug users. Health Place. 2006;12(1):79-85. doi:10.1016/j.healthplace.2004.10.004

14. Kidder DP, Wolitski RJ, Pals SL, Campsmith ML. Housing status and HIV risk behaviors among homeless and housed persons with HIV. J Acquir Immune Defic Syndr. 2008;49(4):451-455. doi:10.1097/QAI.0b013e31818a652c

15. Akaberi A, Seyyed Alinaghi SA, Rahmani R, Rahmani S, Mahmoudi Farahani M, Hosseini SM. Frequency of risk factors of HIV and hepatitis infections among the homeless in Tehran, Iran (2005-2007). Journal of Sabzevar University of Medical Sciences. 2011;18(4):296-301.

16. Garfein RS, Laniado-Laborin R, Rodwell TC, et al. Latent tuberculosis among persons at risk for infection with HIV, Tijuana, Mexico. Emerg Infect Dis. 2010;16(5):757-763. doi:10.3201/ eid1605.091446

17. Story A, Murad S, Roberts W, Verheyen M, Hayward AC. Tuberculosis in London: the importance of homelessness, problem drug use and prison. Thorax. 2007;62(8):667-671. doi:10.1136/thx.2006.065409

18. Etemad K, Eftekhar Ardabili H, Rahimi A, Gouya MM, Heidari A,
Kabir MJ. Attitudes and knowledge of HIV positive persons and high risk behaviors groups in Golestan, Iran. Iran J Epidemiol. 2011;7(1):23-31.

19. Ramezani Tehrani F, Malek-Afzali H. Knowledge, attitudes and practices concerning HIVIAIDS among Iranian at-risk subpopulations. East Mediterr Health J. 2008;14(1):142-156.

20. Khajehkazemi R, Haghdoost A, Navadeh S, et al. Risk and vulnerability of key populations to HIV infection in Iran; knowledge, attitude and practises of female sex workers, prison inmates and people who inject drugs. Sex Health. 2014;11(6):568-574. doi:10.1071/sh14165

21. Amiri FB, Gouya MM, Saifi M, et al. Vulnerability of homeless people in Tehran, Iran, to HIV, tuberculosis and viral hepatitis. PLoS One. 2014;9(6):e98742. doi:10.1371/journal. pone.0098742

22. Shokoohi M, Karamouzian M, Mirzazadeh A, et al. HIV Knowledge, attitudes, and practices of young people in Iran: findings of a national population-based survey in 2013. PLoS One. 2016;11(9):e0161849. doi:10.1371/journal.pone.0161849

23. Haghdoost A, Pourkhandani A, Motaghipisheh S, Farhoudi B, Fahimifar N, Sadeghirad B. Knowledge and Attitude concerning HIVIAIDS among Iranian Population: a Systematic Review and Meta- Analysis. Iran J Epidemiol. 2011;6(4):8-20.

24. Ghabili K, Shoja MM, Kamran P. The Iranian female high school students' attitude towards people with HIVIAIDS: a crosssectional study. AIDS Res Ther. 2008;5:15. doi:10.1186/17426405-5-15

25. Mazloomi-Mahmoodabad SS, Abbasi-Shavazi M. Knowledge and attitude survey of high school students of Yazd province of Iran about HIVIAIDS. Tabib-e-Shargh. 2006;8(1):53-63.

26. Montazeri A. AIDS knowledge and attitudes in Iran: results from a population-based survey in Tehran. Patient Educ Couns. 2005;57(2):199-203. doi:10.1016/j.pec.2004.05.014

27. Liverpool J, McGhee M, Lollis C, Beckford M, Levine D. Knowledge, attitudes, and behavior of homeless AfricanAmerican adolescents: implications for HIV/AIDS prevention. J Natl Med Assoc. 2002;94(4):257-263.

28. Martinez-Donate AP, Hovell MF, Blumberg EJ, et al. Gender differences in condom-related behaviors and attitudes among Mexican adolescents living on the U.S.-Mexico border. AIDS Educ Prev. 2004;16(2):172-186.

29. Allahqoli L, Abed Saeedi Z, Azin A, Hajaan S, Alavi Majd H, Molavi N. Socially damaged women's perception of sexually transmitted infections: a qualitative study. Life Sci J. 2014;11(4s):244-250.

30. Fallahi H, Tavafian S, Yaghmaie F, Hajizadeh E. Attitudes of HIVIAIDS patients towards condom use manuals: a qualitative research. Journal of Isfahan Medical School. 2012;30(179):1-13.

31. Razieh L, Ramezani Tehrani F, Farideh Y, Ebrahim H. Social and environmental barriers to condom use among women at risk for HIV/ AIDS: a qualitative study. Payesh. 2012;11(5):669-678.

32. 32. Razzaghi EM, Rahimi-Movaghar A, Mohammad K, Hosseini M. A qualitative study of risky sexual behaviour in injecting drug users in Tehran. Journal of School of Public Health. 2004;2(2):110.

33. Nyamathi A, Stein JA, Schumann A, Tyler D. Latent variable assessment of outcomes in a nurse-managed intervention to increase latent tuberculosis treatment completion in homeless adults. Health Psychol. 2007;26(1):68-76. doi:10.1037/02786133.26.1.68

34. Peterson Tulsky J, Castle White M, Young JA, Meakin R, Moss AR. Street talk: knowledge and attitudes about tuberculosis and tuberculosis control among homeless adults. Int J Tuberc Lung Dis. 1999;3(6):528-533.

35. Nyamathi A, Sands H, Pattatucci-Aragon A, Berg J, Leake B. Tuberculosis knowledge, perceived risk and risk behaviors among homeless adults: effect of ethnicity and injection drug use. J Community Health. 2004;29(6):483-497.

36. Lee HJ, Moneyham L, Kang HS, Kim KS. Peer supporter experiences of home visits for people with HIV infection. HIV AIDS (Auckl). 2015;7:233-239. doi:10.2147/hiv.s89436 